\title{
Factors Affecting the Continuance to Share Location on Social Networking Sites: The Influence of Privacy Concern, Trust, Benefit and the Moderating Role of Positive Feedback and Perceived Promotion Innovativeness
}

\author{
Jeng-Chung Chen \\ Institute of International Management, National Cheng Kung University \\ E-Mail: victor@mail.ncku.edu.tw \\ Quang-An Ha \\ Institute of International Management, National Cheng Kung University \\ E-Mail: haquangan@gmail.com
}

\begin{abstract}
Location sharing has become an indispensable part of social networking sites (SNSs) that brings business many opportunities and fosters sustainable business activities by increasing the efficiency of location promotion. This study investigated the factors that affect location sharing behavior among SNS users and how to sustain such behavior. The results of our survey of 210 Facebook users recruited from MTurk indicated that privacy concerns and trust in SNS members have significant impacts on the perceived risk of location sharing while trust in SNS providers does not have such an impact on perceived risk related to location sharing. Also, impression management and incentive are significantly associated with the perceived benefits of location sharing. Furthermore, both perceived risk and perceived benefits of location sharing are found to have significant impacts on attitudes toward sharing location. Notably, this study contributes to the post-adoption literature when examining the relationship between attitude toward sharing location and the incentive to continue location sharing behavior under the moderating effect of positive feedback and perceived promotion innovativeness. The results showed that positive feedback and perceived promotion innovativeness are essential factors that enhance the relationship between attitude toward location sharing and continued sharing of location. Detailed discussions and future research directions are provided.
\end{abstract}

Keywords: Location sharing, Benefits, Risks, Privacy concern, Trust in SNS provider and member, Impression management, Incentive, Positive feedback, Perceived promotion innovativeness 


\section{INTRODUCTION}

With the booming use of smartphones and the development of the Global Positioning System (GPS), new services adopting location-based technologies, such as location-based contextual advertising, vehicular navigation systems, and local recommendations, are becoming increasingly popular (Tsai et al., 2009). Along with the rapid growth of social networking sites (SNSs), location-based technology has been developed to integrate into SNSs and has become an indispensable part of these sites. Early examples of location-based SNSs are Foursquare, Loopt, Wikitude.me (Jang \& Lee, 2018). The increasing number of these mobile application users has gradually made the use of location-based services a social norm (Venkatesh, Morris, Gordon, \& Davis, 2003). Such services are considered powerful tools, providing not only users but also marketers and retailers with great opportunities to exploit unprecedented benefits (Tsai et al., 2009).

Many applications that consist of both location-based service (LBS) features and SNSs are widely available in the current market. For marketers, such applications benefit them in terms of better targeting customers through personalized services. Based on personal real-time location data, sales information for nearby shops can be sent to people. Another way of attracting new customers via a location-based service is to capitalize on customer's existing SNS usage by asking people to check-in or give reviews in exchange for coupons or redemption of coupons. These apps allow users to navigate direction, track location based on real-time data, search for recommendations about nearby places and other related information, as well as being informed of locally personalized services (Jang \& Lee, 2018; Tsai, Kelley, Cranor, \& Sadeh, 2010). Also, users can share information about any places they have experienced on SNSs. This information will help reduce the time required for others to find places or prevent them from experiencing undesirable locations. Due to these benefits to society, locationbased services are considered eco-friendly business activities, which is a trend in the modern technological industry (Jang \& Lee, 2018). Along with the growth of locationbased platforms, however, there is increasing concern about such systems. Location information could be manipulated for stalking, tracing routes, or identifying a user's real identity. Once location data is intentionally used for these harmful purposes, it can be used to seriously hurt people or cause large-scale loss of privacy (Puttaswamy \& Zhao, 2010).

Due to both the benefits and risk concerns, research on location-based sharing platforms has been receiving significant attention. Dominant concepts related to location sharing involve motivation (Bilogrevic, Huguenin, Mihaila, Shokri, \& Hubaux, 2015; Patil, Norcie, Kapadia, \& Lee, 2012), personality traits (Chorley, Whitaker, \& 
Allen, 2015), privacy (Wang \& Lin, 2017; Zhou, 2017), trust, benefits, and social influence (Beldad \& Citra Kusumadewi, 2015), and self-disclosure (Chen, Su, \& Quyet, 2017; Wang, Duong, \& Chen, 2016). Several studies on location-based services drawing from the Privacy Calculus Model, the Technology Acceptance theory, and the Elaboration Likelihood model have investigated different outcomes related to users' location sharing behavior. The common dependent variables taken into consideration include LBS adoption (Beldad \& Citra Kusumadewi, 2015; Jang \& Lee, 2018; Xu \& Gupta, 2009; Xu, Teo, \& Tan, 2005; Zhou, 2011) and intention to disclose information (Chang \& Chen, 2014; Chen et al., 2017; Koohikamali, Gerhart, \& Mousavizadeh, 2015). Therefore, we aim to enrich the existing literature on location sharing behavior by examining the role of users' perceived risk and benefit on their likelihood of continuing sharing information. Specifically, drawing from the privacy calculus model, we posit that privacy concern, trust in the SNS provider, and trust in SNS members are the antecedents of perceived risk, while perceived benefits are predicted based on impression management and incentive.

Additionally, continuance usage is considered to be a critical element in assessing the sustainability of an online platform, which has not been treated in much detail in prior literature. To date, only a few studies have taken into account the issue of continuance usage of local sharing on SNSs. Yun, Han, and Lee (2013) found that while social influence doesn't impact user willingness to continuously use locationbased services, performance expectancy (i.e., a user's belief that technology can help to accomplish a goal), and effort expectancy (i.e., a user's perceived ease of use) can significantly predict such behavior. Contradictory to this finding, the relationship between perceived usefulness and continuance intention toward Facebook check-in is not supported in Lin, Lu, Hsiao, and Hsu (2014). Another study by Wang and Lin (2017) demonstrated perceived trust as the antecedent of continued usage intention.

In summary, the findings for continuance usage in the context of location-based services is somewhat inconsistent and insufficient. Therefore, this study also contributes to the current literature on IS continuance usage in the context of post-adoption location sharing behavior and related factors. Previous research has shown that the favorable attitude derived from receiving positive feedback may help sustain user location sharing in the future (Tsai et al., 2009). In addition, location sharing is being increasingly adopted by marketers as an innovative way to approach customers. Previous studies have also shown the impact of perceived innovativeness on user outcome behavior $(\mathrm{Fu}$ \& Elliott, 2013; Lafferty \& Goldsmith, 2004). Therefore, this study is also an attempt to investigate the moderating role of positive feedback and perceived promotion 
innovativeness on user outcome behavior, which in this case is the relationship between attitude and intention to continuously share location information.

\section{THEORETICAL BACKGROUND}

\section{SNS and Location Sharing}

The combination of two trends, personal GPS support devices and SNSs, has triggered the rise of the location-based SNS. It is a form of SNS that focuses on location sharing as the main interaction in the community (Yavuz \& Toker, 2014). In addition to the existing functions of location-based platforms (e.g. navigation, nearby information search, location-based advertising), integrating the features of SNSs provides users with a greater variety of choices. Consistent with characteristics of SNSs proposed by Boyd and Ellison (2007), users in location-based SNSs can build and manage a public or semi-public profile and interact with other users in their list of connections. Specifically, people can check-in, which is sharing their location on a social site, view the location posts of their contacts, leave comments, and give ratings to the shared places. Later, besides established platforms specialized in location services such as Foursquare, Loopt, Wikitude.me, popular SNSs have also launched various location-related functions, including the Facebook location tag, Facebook Nearby, and Instagram Photo Maps.

Along with the rapid growth of this phenomenon, increasing research interest in location-based services is developing in the field of both marketing and information systems. Previous research has mainly drawn from the technology acceptance model (TAM) (Jang \& Lee, 2018), the privacy calculus model (Chen et al., 2017; Sun, Wang, Shen, \& Zhang, 2015), justice theory (Zhou, 2012), and the Big Five personality traits (Chorley et al., 2015). Many studies have attempted to investigate the motivation behind location sharing behavior. The findings have indicated online impression management (Beldad \& Citra Kusumadewi, 2015), the need for popularity (Christofides, Muise, \& Desmarais, 2009), and incentive (Patil et al., 2012; Zhao, Lu, \& Gupta, 2012) are strong motives for users' decisions to share their location. Due to the sensitive nature of location information, it is undeniable that location sharing will raise privacy concerns among users. Location sharing has also been found to be the major risk perceived by location service users (Xu, Michael, \& Chen, 2013). Information collection and secondary use are two dimensions of privacy concern that exert a significant impact on users (Zhou, 2011). A recent study by Jung and Park (2018) suggested cognition-affect appraisal as a promising framework in which to further study user privacy concerns related to location-based services. This study noted that different privacy concerns will be associated with various effects, which in turn give rise to different coping behaviors, 
namely refusal, restricted use, complaints, negative word-of-mouth, no response, and mental disagreement.

\section{Privacy Calculus Model}

The privacy calculus model, proposed by Laufer and Wolfe (1977), is widely applied to explain how an individual decides to reveal his/her personal information. Based on the model, one will consider the trade-off between expected risks and benefits that such disclosure brings. These two factors always exist simultaneously and impact privacy management (Waters \& Ackerman, 2011). A decision to reveal information and how much information will be provided will depend on the degree of perceived benefits (Li, 2012). Extant literature has utilized this model to examine user disclosure behavior in various online contexts, such as mobile applications (Keith, Thompson, Hale, Lowry, \& Greer, 2013; Wang et al., 2016), SNS (Dienlin \& Metzger, 2016; Min \& Kim, 2015; Xu et al., 2013) and e-commerce (Dinev \& Hart, 2006).

With regard to location sharing behavior, prior studies have separately examined risks and benefits (Beldad \& Citra Kusumadewi, 2015; Keith, Babb Jr, Furner, \& Abdullat, 2010). By drawing upon the privacy calculus perspective, recent research has investigated these two issues using one integrated model. In a study on location-based SNSs in China, it was revealed that both utilitarian and hedonic benefits positively influence perceived benefits. Also, it was found that privacy risks exert a positive moderating effect on the relationship between perceived benefits and the propensity to disclose information (Sun et al., 2015). Zhao et al. (2012) demonstrated that incentive provision and interaction promotion are closely associated with personalization and connectedness, while privacy control and privacy policy significantly diminish users' privacy concerns about sharing location information. In a recent study conducted in Vietnam, Chen et al. (2017) found that connectedness, localtability, and personalization are three major aspects of benefits, while privacy concerns, as expected, significantly reduce disclosure intention. Interestingly, legislation awareness does not exert any impact on user privacy concerns or disclosure intention. Despite the fact that a variety of factors influencing users' perceived risks and benefits were found in the past literature, it has been relatively consistent that in the findings that compared to benefits, the extent to which risks impact user behavior tend to be smaller.

\section{Antecedent of Perceived Risk}

\section{Privacy concern}


Since location-based services first became available, information privacy, especially, location information, has become a primary concern among users (Barkhuus \& Dey, 2003). Information privacy reflects the extent to which one assumes full control of his/her personal data (Stone, Gueutal, Gardner, \& McClure, 1983). Information privacy is commonly viewed as a multidimensional construct. Smith, Milberg, and Burke (1996) suggested that data collection errors, unauthorized secondary internal use, unauthorized secondary external use, and improper access are four main issues of related to concerns about information privacy. Later, Malhotra, Kim, and Agarwal (2004) argued that there are three dimensions of privacy concern, including collection, control, and awareness, that should be taken into consideration. While collection and secondary use are the main antecedents of perceived risk, errors significantly influence user trust in service providers (Zhou, 2011). Similarly, Raschke, Krishen, and Kachroo (2014) found that among the four types of privacy concerns mentioned above, collection and unauthorized use are the two factors diminishing the likelihood to disclose information among location-based service users.

Privacy concerns comprise one of the critical constructs influencing the behavioral intention of users in an online setting. Extant empirical research has shown extensive evidence supporting its direct relationship in numerous contexts (Chen et al., 2017; Dienlin \& Metzger, 2016; Min \& Kim, 2015; Yun et al., 2013). Besides a direct impact on user behavior, privacy concerns also have indirect influences on user behavior through trust, perceived usefulness, and perceived risk (Zhou, 2011). Privacy concern and privacy risk have been empirically examined and proved to have a positive correlation in prior studies on some information systems, including e-commerce (Fortes \& Rita, 2016; Van Slyke, Shim, Johnson, \& Jiang, 2006) and SNSs (Zhou \& Li, 2014). Similarly, in the context of location-based SNSs, we posit that when users have a higher degree of concern users about a platform, they will perceive more risk. Hence, we propose the following hypothesis:

H1: Privacy concern has a positive impact on perceived risk related to location sharing.

\section{Trusting belief}

Early studies on e-commerce mainly emphasized concerns related to privacy threats and argued that it is the main inhibitor of online transactions (Dinev \& Hart, 2006). However, despite the existence of this risk, the volume of online transactions continues to grow. Trust is one of the cost-mitigating factors that can significantly contribute to lessening the influence of risk on user behavior. Existing evidence suggests that trust is a determinant of perceived risk (Beldad, de Jong, \& Steehouder, 2011) and that it can directly facilitate user's disclosure intention (Bansal \& Gefen, 
2010; Krasnova, Veltri, \& Günther, 2012), participation in web surveys (Fang, Shao, \& Lan, 2009), online transactions (Beldad et al., 2011) online shopping intention (Pengnate \& Sarathy, 2017), and repurchase likelihood (Hsu, Chang, Chu, \& Lee, 2014). Different settings such as SNSs, e-government services, and online health system have been investigated. However, trust in the context of location-based information sharing has not been extensively investigated. Most of the studies on this subject mainly view trust as a single construct, for example, Jang and Lee (2018), Zhou (2012) and Xu et al. (2005). In this study, following Dinev and Hart (2006) approach, we view two aspects of trust: trust in the service provider (SNS) and trust in members on SNSs.

Since service providers have unlimited access to the personal data of users, their role is critically important in building user trust. The notion of trust towards service providers can be explained by employing two dimensions suggested in McLain and Hackman (1999): organizational ability and willingness to protect user's data. Ability manifests in the way a provider can adopt highly protective practices and have the competence to guarantee that use data is safe from harm. On the other hand, willingness means regardless of having full control of user information, the service provider does not disclose their personal data to another party without prior consent under any circumstances.

Location-related information is considered to be sensitive data in that once manipulated, it could be used to generate users' pattern of use and help to understand their behavior, lifestyle, habits, and reveal their personal identity (Xu, 2010). This data type possibly benefits location-based service providers, wireless carriers, and mobile devices suppliers (Beldad \& Citra Kusumadewi, 2015). Given the sensitive nature of location information, in order to encourage users to share such information, they should be ensured that their data is warranted against prospective breaches and harmful manipulation. Belief in a service provider's ability and willingness to protect personal data tends to diminish users' perceived risk when come to sharing location on SNSs. Thus, we propose the following hypothesis:

H2: Trust in an SNS provider has a negative impact on perceived risk associated with location sharing.

Since one of the most prominent characteristics of SNSs is member interaction, it is important to take trust in other members into consideration in research on this topic. SNSs comprise open platforms where individual information is visible to a certain number of online participants. Users' activities can therefore be followed, secretly shared for the purpose of gossip, or manipulated for harmful purposes by other members 
(Fusco, Michael, \& Michael, 2010; Krasnova et al., 2012). In location-based SNSs, the location tracking or sharing function could provide data that could be used to trace the whereabouts or preferential routes of users, which might place a user in a risky situation. Recent research by Beldad and Citra Kusumadewi (2015) is the first study on locationbased services looking into trust in other members. Their findings demonstrate that though not as statistically significant as trust in service providers, trust in other members still positively impacts the use of location sharing applications. In this study, we thus propose the following hypothesis:

H3: Trust in SNS members has a negative impact on perceived risks associated with location sharing.

\section{Perceived Benefit}

\section{Impression management}

The notion of impression management or self-presentation first appeared in interpersonal behavior studies and is defined as the process by which people try to influence others' impressions of them in a favorable way (Leary \& Kowalski, 1990). For example, in the SNS setting, users may share information or post photos with the aim of creating a socially desirable self-image such as beauty, popularity, thoughtfulness, or well-roundedness (Wang \& Stefanone, 2013). In SNSs, people nearly have full control over what they want to disclose; hence, they tend to reveal information that is favorable to them. When people reveal their location, which could be any place they are visiting, they may want others to understand or have an impression of their lifestyle and social life (Wang \& Stefanone, 2013). It should be noted that these places may not be those they strongly prefer but rather those they feel may be interesting to other users and help to create desirable self-images.

Past studies have revealed that a higher degree of self-disclosure on Facebook will result in the greater extent of exhibitionistic motivation (i.e. motivation to publicize one's individual private life) and later check-in behavior (Wang \& Stefanone, 2013). A study conducted by Beldad and Citra Kusumadewi (2015) also demonstrated that among four types of proposed benefits from online location sharing activities (impression management, entertainment, information search, information dissemination), only impression management and entertainment significantly influence location sharing among Indonesian students. In this study, we propose the following hypothesis:

H4: Impression management has a positive impact on perceived benefits associated with location sharing. 


\section{Incentive}

Incentives can be defined as rewards given to participants for taking part in an activity. Online services usually encourage user involvement by offering monetary or nonmonetary incentives, such as gaining extra points for free upgrades, earning badges or virtual items, or downloading some specialized features (Zhao et al., 2012). With regard to online information disclosure, users may be asked to share specific information to receive rewards, which could be financial advantages (e.g. cash pay-outs or reductions in service charges) or information benefits (e.g. access to information sources that are not widely public) (Sheehan \& Hoy, 2000). Recently, check-in on SNSs has been adopted by many restaurants, clothing shops, and many other stores as a way to promote their services. Customers are asked to check-in in exchange for a specific discount or free items. By this way, service providers can capitalize on their customers' SNSs, so more people will know about their services.

From a cost-benefit perspective, incentive is explained as the compensation for a user's loss of privacy as well as benefits derived from disclosing private information. Prior studies on location-based services have found that the practice of offering compensation or incentives could influence users' perceived benefits, which in turn may increase the likelihood of disclosing location information (Koohikamali et al., 2015; Xu, Teo, Tan, \& Agarwal, 2009; Zhao et al., 2012). In Zhao et al. (2012) study on Digu, a location-based website in China, among different benefit and privacy factors, incentive provision was found to be the strongest antecedent of a user's propensity to reveal information. In another qualitative study, participants stated firmly that the reasons for using Foursquare, a location-based social network, is their special offers or earning badges, which makes them feel proud of themselves and as if they are in a competitive game (Lindqvist, Cranshaw, Wiese, Hong, \& Zimmerman, 2011). Thus, we argue that the existence of incentives will make people more aware of the benefits they may be able to gain when making a decision to share location information on a social network. The next hypothesis is as follows:

H5: Incentive has a positive impact on perceived benefits associated with location sharing.

\section{Privacy calculus and attitude toward location sharing}

Privacy risk is defined as a situation where personal information is leaked and used for harmful purposes (Xu et al., 2005; Zhou, 2012). In the context of SNSs, this risky situation could be caused by a lack of competence and willingness on the part of the service provider or illegal or unethical purposes of third party or other users within one's 
social network. A considerable body of study on disclosure behavior in an online setting has empirically investigated the relationship between perceived risk and the behavioral intentions of users. Privacy risk has been found to negatively influence user disclosure behavior on mobile application (Keith et al., 2013), on e-government transactions (Beldad et al., 2011), intention to purchase online (Fortes \& Rita, 2016), adopt internet banking services (Giovanis, Binioris, \& Polychronopoulos, 2012), and continuance usage of mobile SNSs (Zhou \& Li, 2014). In addition to this direct relationship, a recent study also demonstrated the potential moderating effect of privacy risk on the positive correlation between perceived benefit and intention to disclose location information among Chinese users (Sun et al., 2015). Raschke et al. (2014) argued that perceived privacy risk will negatively lead to the likelihood of sharing location information via concerns related to collection. To briefly summarize, we posit that the more risk users associate with the idea of sharing their location on SNSs, the less willing they will be to do so. Thus, the next hypothesis is as follows:

H6: Perceived risks associated with location sharing have a negative impact on attitudes toward sharing location.

According to the privacy calculus model, one will disclose his or her personal information only when the greater benefit of sharing is perceived. Previous studies have revealed a variety of benefits explaining location sharing behavior. A user may feel that sharing information about past locations could positively impact society in that it helps others reduce the time required for searching, and they will be more reviews to consider before going to a given place (Koohikamali et al., 2015). Besides benefits users believe that they can contribute to society, they will choose to reveal information due to the advantages they can gain. When users share their location information in their network, they can gain the benefit of incentive (Koohikamali et al., 2015), impression management, entertainment (Beldad et al., 2011; Wagner et al., 2010), personalization, and connectedness (Zhao et al., 2012). Prior empirical research employing the privacy calculus model has consistently demonstrated that the impact of perceived benefit is stronger than privacy risk (Chen et al., 2017; Sun et al., 2015; Xu \& Gupta, 2009; Zhao et al., 2012). In this study, we also argue that people will have a more favorable attitude toward information disclosure on location-based SNSs if they believe in the value of such a practice. We thus propose the following hypothesis:

H7: Perceived benefits associated with location sharing have a positive impact on attitude toward sharing location.

\section{Attitude toward location sharing and intention to continue sharing}


Information system continuance is a critical construct in the literature on information systems, and is defined as the extent to which users plan to continuously use such systems in the future. While the initial adoption of an information system is an important first step, the factor determining the eventual success of an electronic firm lies in continuance usage (Bhattacherjee, 2001). This is because additional expenses for market research, new account setup, promotional campaigns, exploring new markets, or gaining new customers usually generates much higher cost than retaining current customers (Bhattacherjee, 2001). In addition, in the era of technology, with a high rate of new product development, the market for technology products is highly competitive. Customers can easily adopt new services but also can quickly switch to another product if their experience is unsatisfactory. Encouraging users to continue using is considered to play a central role in firm survival. Given the above reasons, it is of critical importance that more effort is spent examining the issue of continuance usage.

The relationship between attitude and continuance usage intention has been well examined in several studies on information systems (Chen \& Li, 2010; Hsu, Yen, Chiu, \& Chang, 2006; Lee \& Tsai, 2010). In the context of location-based services, we also argue that a more favorable attitude will lead to a greater likelihood of continuously sharing location information on social networking sites. Thus, the next hypothesis is:

H8: Attitude toward location sharing has a positive impact on Continued sharing of location.

\section{Moderation effect of positive feedback and perceived promotion innovativeness}

Thus far, the moderating effect of user behavior has not received much attention in the literature on location sharing behavior. Only a few moderators have been integrated into the research model used in recent studies. For instance, innovativeness has been found to moderate the relationship between reputation, trust, entertainment, and user attitudes towards LBS services (Jang \& Lee, 2018), and privacy risk has been shown to moderate the link between users' perceived benefits and self-disclosure behavior (Sun et al., 2015). In addition, the positive impact of performance expectancy on continuous usage intention will be stronger in those with lower levels of privacy concern (Yun et al., 2013). In this study, we propose investigating two prospective moderators: positive feedback and promotion innovativeness. To date, these two factors have not been studied extensively in the context of location sharing behavior.

\section{Positive Feedback}


In a location-based SNS, feedback is provided about who is requesting a user to share his/her location (Tsai et al., 2009). Awareness that shared content is viewed by many people will potentially make users feel that they are helping their online community, which in turn could encourage them to be more proactive on the platform, thus increasing their benefits and degree of loyalty (Ha \& Chen, 2016). Furthermore, making historic activities visible is argued to be one of three characteristics of a "socially translucent system" designed to support communication via computer networks (Erickson \& Kellogg, 2000). Site transparency, in turn, will help to decrease privacy concerns related to the misuse of personal information. In a study adopting field deployment of a mobile location sharing system, the group having access to a history of requests was found to exhibit greater levels of comfort and a lower degree of privacy concerns than a group given no feedback (Tsai et al., 2009). Specifically, participants in the former group felt comfortable with being located not only by those on their social contact list but also by strangers.

It should be noted that the presence of feedback should be carefully taken into consideration. The reason is that various feedback content, which could have no meaning or offer negative or positive feedback, could exert a distinct impact on user behavior (Johnson \& Van Der Heide, 2015). Hence, in the scope of this study, we only focus on investigating positive feedback. When a more favorable attitude is derived from receiving positive feedback, it will be more likely that users will continue location sharing in the future (Tsai et al., 2009). Further, favorable attitudes derived from receiving positive feedback may increase satisfaction with the system, a key factor that positively influences continuance usage related to information systems (IS) (Chen, Elakhdary, \& Ha, 2019; Limayem \& Cheung, 2008; Mouakket, 2015). Based on the above discussion, we propose the following hypothesis:

H9: Positive feedback for users' location sharing has a positive impact on the relationship between attitude towards location sharing and continued sharing of location.

\section{Perceived promotion innovativeness}

Innovation plays an indispensable role in creating a sustainable competitive advantage for any firm, especially in the information technology industry (Mahmod, Ibrahim, \& Yousif, 2010). However, in order for a firm to gain such an advantageous position, it is important that users or customers perceive the offering as innovative (O'Cass \& Carlson, 2012). The extent to which one subjectively assesses a product or service as having adopted innovative features is defined as perceived innovativeness $(\mathrm{Wu}$, Balasubramanian, \& Mahajan, 2004). Existing literature has provided ample evidence 
of the impact of perceived innovativeness on users' behavioral outcomes, such as technology adoption (Chihui, 2009; Seliaman \& Al-Turki, 2012), willingness to purchase (Fu \& Elliott, 2013; Lafferty \& Goldsmith, 2004), and the seller-buyer relationship (Falkenreck \& Wagner, 2011).

Past studies on location-based SNSs have investigated the moderating effect of personal innovativeness (i.e. users' tendency to experience new services) on location awareness and attitude towards the service. In this study, we approach innovativeness in the sense of a service provider's characteristics. As mentioned before, marketers are increasingly adopting the sharing of location as a way to help more people know about their businesses. Besides earning incentives, consumers will be more willing to checkin their location if they perceive the innovativeness of the service they are investigating and want to let others know and encourage them to give it a try. The more changes and unique features of a service an individual perceive over time, the more likely he/she will be to continue sharing its location on a SNS.

H10: Perceived promotion innovativeness has a positive impact on the relationship between attitude towards location sharing and continued sharing of location.

\section{RESEARCH METHODOLOGY}

\section{Sample and Data Collection Procedure}

We collected data using an online survey in the USA due to the popularity of location-based SNSs here. Using the MTurk platform, we obtained 230 responses, and after data cleaning, we retained 210 samples for further analysis. All participants used Facebook as the platform on which to share their locations. The demographic data of the respondents is shown in Table 1. 


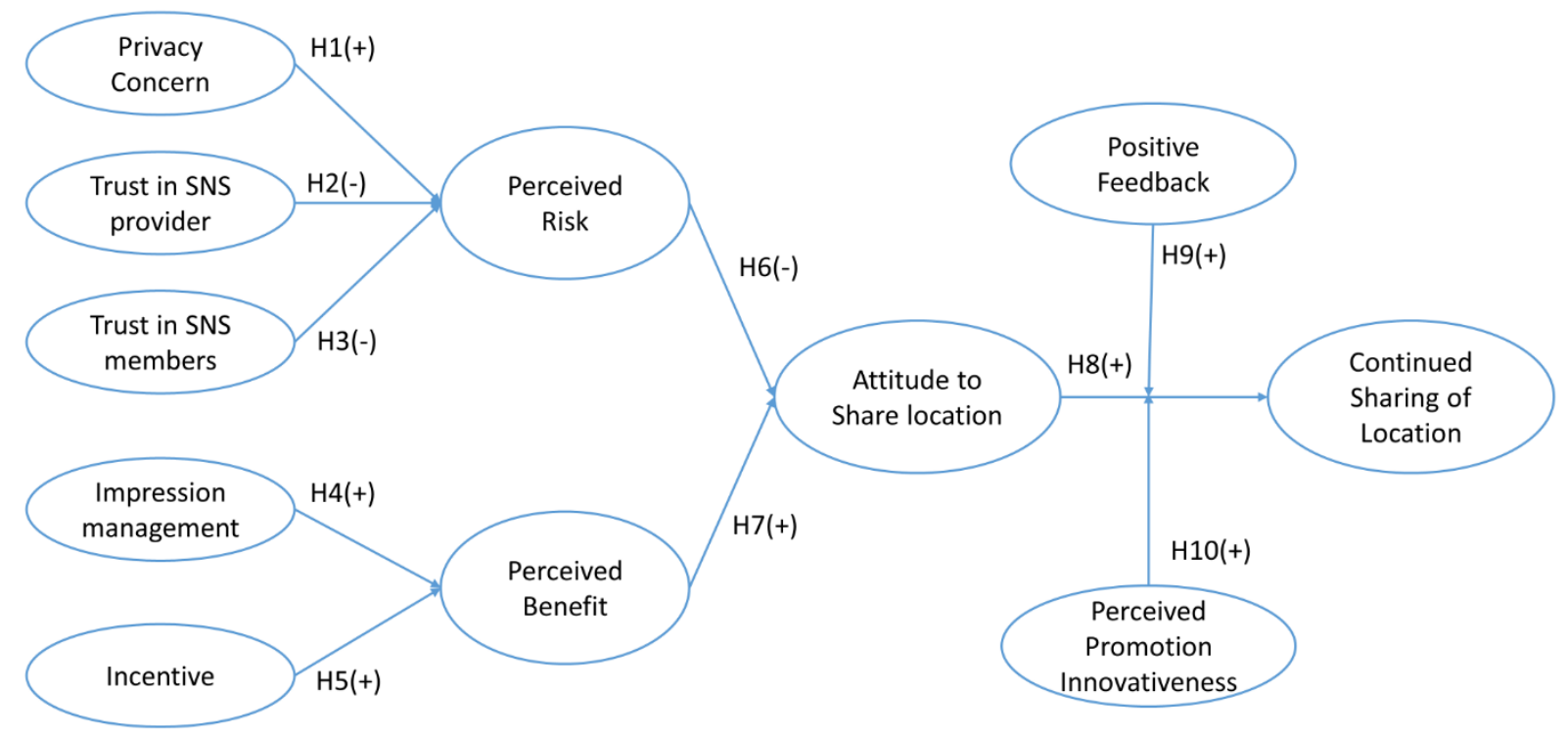

Figure 1. Research Framework

Table 1. Demographics

\begin{tabular}{lcc}
\hline Characteristics & Frequency $\mathbf{( N = 2 1 0 )}$ & Percent (100\%) \\
\hline Gender & 84 & \\
Male & 126 & 40.0 \\
Female & & 60.0 \\
\hline Age & 3 & \\
Under 20 & 89 & 1.4 \\
$21-30$ & 74 & 42.4 \\
$31-40$ & 23 & 35.2 \\
$41-50$ & 21 & 11.0 \\
$>50$ & & 10.0 \\
\hline
\end{tabular}

\section{Education}

High school or below

Bachelor's degree

Master's degree

Doctoral degree

6

2.9

\section{Employment Status}

Unemployed

Part-time employment

Student

Full-time employment 


\begin{tabular}{|c|c|c|}
\hline Characteristics & Frequency $(\mathrm{N}=210)$ & Percent $(100 \%)$ \\
\hline \multicolumn{3}{|l|}{ Working experience (years) } \\
\hline $1-5$ & 63 & 30.0 \\
\hline $5-10$ & 54 & 25.7 \\
\hline $10-20$ & 42 & 20.0 \\
\hline$>20$ & 50 & 23.8 \\
\hline \multicolumn{3}{|l|}{ Income } \\
\hline Less than USD 500 & 14 & 6.7 \\
\hline USD 500-1000 & 26 & 12.4 \\
\hline USD 1001-2000 & 44 & 21.0 \\
\hline USD 2001-3000 & 62 & 29.5 \\
\hline USD 3000-4000 & 20 & 9.5 \\
\hline Above 4000 & 44 & 21.0 \\
\hline \multicolumn{3}{|c|}{ Average time spent using social network sites per day } \\
\hline$<1$ hour & 35 & 16.7 \\
\hline From 1 to 2 hours & 83 & 39.5 \\
\hline From 2 to 3 hours & 53 & 25.2 \\
\hline From 3 to 5 hours & 23 & 11.0 \\
\hline$>5$ hours & 16 & 7.6 \\
\hline \multicolumn{3}{|c|}{ Frequency of check-in per month } \\
\hline fewer than 1 time per month & 47 & 22.4 \\
\hline 1-2 times per month & 89 & 42.4 \\
\hline 3-4 times per month & 36 & 17.1 \\
\hline 5-6 times per month & 17 & 8.1 \\
\hline 7-8 times per month & 6 & 2.9 \\
\hline More than 8 times & 15 & 7.1 \\
\hline
\end{tabular}

\section{Measurement Items}

We adapted and revised the measurement items from previous studies and used a 7-point Likert scale (ranging from Strongly disagree to Strongly agree) for these measurement items (Table 2). 
Table 2. Measurement Items

\begin{tabular}{|c|c|c|}
\hline Construct & Measurement & Source \\
\hline Privacy & pc1. I am concerned about my privacy. & (Buchanan, \\
\hline \multirow[t]{7}{*}{ Concern } & pc2. I am concerned about strangers knowing my location. & Paine, Joinson, \\
\hline & pc3. I am concerned about people I do not know obtaining my & \& Reips, 2007) \\
\hline & personal information from my online activities. & \\
\hline & pc4. I am not worried about people I don't know obtaining my location & \\
\hline & (R). & \\
\hline & pc5. I am concerned about being tracked based on my location by the & \\
\hline & SNS site application I use. & \\
\hline \multirow{8}{*}{$\begin{array}{l}\text { Trust to SNS } \\
\text { provider }\end{array}$} & tp1. The SNS provider I'm using is competent in protecting my & (Beldad \& Citra \\
\hline & location information. & Kusumadewi, \\
\hline & tp2. The SNS provider I'm using has the knowledge of how to protect & 2015) \\
\hline & users’ location information. & \\
\hline & tp3. The SNS provider I'm using knows how to protect its users' & \\
\hline & privacy. & \\
\hline & tp4. The SNS provider I'm using uses the right technology to protect & \\
\hline & my information from third-party access. & \\
\hline \multirow{3}{*}{$\begin{array}{l}\text { Trust to SNS } \\
\text { member }\end{array}$} & tm1. In general, users on my SNS do care about my privacy. & (Beldad \& Citra \\
\hline & tm2. Users on my SNS are sincerely concerned about my privacy. & Kusumadewi, \\
\hline & tm3. Users on my SNS will not protect my privacy (R). & 2015) \\
\hline Impression & im1. Sharing my location on SNSs makes me a likable person. & (Beldad \& Citra \\
\hline \multirow[t]{5}{*}{ Management } & im2. Sharing my location on SNSs contributes to my image as a cool & Kusumadewi, \\
\hline & person. & 2015) \\
\hline & im3. Sharing my location on SNSs makes me socially desirable. & \\
\hline & im4. Sharing my location on SNSs improves my image as a pleasant & \\
\hline & 到 & \\
\hline \multirow[t]{3}{*}{ Incentive } & ic1. Locations I visit often offer instant discounts for “checking-in” & (Koohikamali et \\
\hline & when I check in on SNSs. & al., 2015); \\
\hline & ic2. Locations I visit offer future coupons when I check in on SNSs. & \\
\hline \multirow{5}{*}{$\begin{array}{l}\text { Perceived } \\
\text { benefit }\end{array}$} & be1. I benefit others when I check-in on SNSs. & (Koohikamali et \\
\hline & be2. Using locally-based SNS applications offers many advantages to & al., 2015); \\
\hline & society. & \\
\hline & be3. When I check in on SNSs, others benefit from the information & \\
\hline & that I share. & \\
\hline
\end{tabular}




\begin{tabular}{|c|c|c|}
\hline Construct & Measurement & Source \\
\hline & $\begin{array}{l}\text { be4. In general, when people check-in on SNSs, they help others } \\
\text { around them. } \\
\text { be5. Using locally-based SNS applications is a beneficial activity for } \\
\text { society as a whole. } \\
\text { be6. Overall, I feel that location check-in on SNSs is beneficial. }\end{array}$ & \\
\hline Perceived Risk & $\begin{array}{l}\text { rk1. Disclosing my location information on SNSs may result in many } \\
\text { unpredictable problems. } \\
\text { rk2. Disclosing my location information on SNSs is risky. } \\
\text { rk3. Disclosing my location information to this on SNSs may result in } \\
\text { potential losses. }\end{array}$ & (Zhou, 2013) \\
\hline $\begin{array}{l}\text { Positive } \\
\text { feedback }\end{array}$ & $\begin{array}{l}\text { pf1. When I share my location on SNSs, I often get positive feedback } \\
\text { from others. } \\
\text { pf2. When I share my location on SNSs, my friends often have a good } \\
\text { word for me. } \\
\text { pf3. When I share my location on SNSs, my friends often give me } \\
\text { some "likes". }\end{array}$ & $\begin{array}{l}\text { (Liu \& Brown, } \\
\text { 2014; Wang et } \\
\text { al., 2018) }\end{array}$ \\
\hline $\begin{array}{l}\text { Perceived } \\
\text { promotion } \\
\text { innovativeness }\end{array}$ & $\begin{array}{l}\text { pi1. This restaurant implements an innovative marketing program. } \\
\text { pi2. This restaurant offers innovative deals. } \\
\text { pi3. This restaurant has an innovative promotion. }\end{array}$ & $\begin{array}{l}\text { (Kim, Tang, \& } \\
\text { Bosselman, } \\
\text { 2018) }\end{array}$ \\
\hline $\begin{array}{l}\text { Attitude to } \\
\text { Share Location }\end{array}$ & $\begin{array}{l}\text { at1. It is a good idea to share my location on SNSs. } \\
\text { at2. I believe that sharing my location on SNSs is wise. } \\
\text { at3. I have a positive attitude toward sharing my location on SNSs. } \\
\text { at4. Sharing my location on SNSs is fun. } \\
\text { at5. I like to share my location on SNSs. }\end{array}$ & $\begin{array}{l}\text { (Koohikamali et } \\
\text { al., 2015); }\end{array}$ \\
\hline $\begin{array}{l}\text { Continued } \\
\text { sharing of } \\
\text { location }\end{array}$ & $\begin{array}{l}\text { ac1. I check-in every time I use an SNS. } \\
\text { ac2. I rarely “check-in” when I use an SNS. } \\
\text { fre. Frequency check in last month }\end{array}$ & $\begin{array}{l}\text { Koohikamali et } \\
\text { al. (2015) }\end{array}$ \\
\hline
\end{tabular}

\section{RESULTS AND ANALYSIS}

\section{Descriptive Statistics, Reliability and Discriminant Validity}

In this study, SmartPLS 3.0 (Ringle, Sven, \& Jan-Michael, 2015) was used for the data analysis. A CFA was performed to assess the reliability and discriminant validity of the measurement. Following criteria suggested by Hair, Ringle, and Marko (2011), we found all the standardized indicator loadings to be higher than 0.70 . The Cronbach's 
alpha and composite reliability (C.R.) of all constructs also were greater than 0.7 and thus guaranteed high reliability of the measurements (Bagozzi, 2011; Fornell \& Larcker, 1981). The average variance extracted (AVE) of all constructs was greater than the suggested criterion 0.50 (Chin, 1998), which showed that all constructs met the requirements of convergent validity. Table 3 shows the results of the descriptive statistics and reliability measurements.

Table 3. Descriptive Statistics and PLS-CFA Results

\begin{tabular}{|c|c|c|c|c|c|c|c|}
\hline Construct & Items & Mean & SD & $\begin{array}{c}\text { Factor } \\
\text { Loading }\end{array}$ & AVE & C.R. & $\begin{array}{c}\text { Cronbach’ } \\
\text { s Alpha }\end{array}$ \\
\hline \multirow[t]{5}{*}{ Privacy Concern (PC) } & pc1 & 4.895 & 1.866 & 0.832 & \multirow{5}{*}{0.750} & \multirow{5}{*}{0.937} & \multirow{5}{*}{0.916} \\
\hline & pc2 & 5.005 & 1.903 & 0.917 & & & \\
\hline & pc3 & 4.829 & 1.922 & 0.897 & & & \\
\hline & pc4r & 4.848 & 2.018 & 0.824 & & & \\
\hline & pc5 & 4.876 & 1.895 & 0.856 & & & \\
\hline \multirow[t]{4}{*}{ Trust in SNS provider (TP) } & tp1 & 4.343 & 1.585 & 0.906 & \multirow{4}{*}{0.763} & \multirow{4}{*}{0.928} & \multirow{4}{*}{0.906} \\
\hline & tp2 & 4.748 & 1.540 & 0.801 & & & \\
\hline & tp3 & 4.633 & 1.609 & 0.878 & & & \\
\hline & tp4 & 4.471 & 1.596 & 0.904 & & & \\
\hline \multirow[t]{3}{*}{ Trust in SNS member (TM) } & $\operatorname{tm} 1$ & 4.400 & 1.640 & 0.780 & \multirow{3}{*}{0.719} & \multirow{3}{*}{0.884} & \multirow{3}{*}{0.817} \\
\hline & $\operatorname{tm} 2$ & 4.295 & 1.568 & 0.886 & & & \\
\hline & $\operatorname{tm} 3 r$ & 4.210 & 1.732 & 0.873 & & & \\
\hline \multirow[t]{4}{*}{ Impression Management (IM) } & $\operatorname{im} 1$ & 3.567 & 1.774 & 0.884 & \multirow{4}{*}{0.852} & \multirow{4}{*}{0.958} & \multirow{4}{*}{0.942} \\
\hline & $\operatorname{im} 2$ & 3.514 & 1.825 & 0.929 & & & \\
\hline & $\operatorname{im} 3$ & 3.610 & 1.848 & 0.935 & & & \\
\hline & $\operatorname{im} 4$ & 3.776 & 1.804 & 0.944 & & & \\
\hline \multirow[t]{2}{*}{ Incentive (IC) } & ic1 & 3.581 & 2.011 & 0.970 & \multirow{2}{*}{0.938} & \multirow{2}{*}{0.968} & \multirow{2}{*}{0.934} \\
\hline & ic2 & 3.724 & 2.059 & 0.967 & & & \\
\hline \multirow[t]{6}{*}{ Perceived benefit (PB) } & be1 & 3.429 & 1.855 & 0.875 & \multirow{6}{*}{0.815} & \multirow{6}{*}{0.963} & \multirow{6}{*}{0.954} \\
\hline & be2 & 3.895 & 1.824 & 0.852 & & & \\
\hline & be3 & 3.819 & 1.816 & 0.894 & & & \\
\hline & be4 & 3.729 & 1.876 & 0.939 & & & \\
\hline & be5 & 3.786 & 1.821 & 0.924 & & & \\
\hline & be6 & 3.719 & 1.828 & 0.928 & & & \\
\hline \multirow[t]{2}{*}{ Perceived Risk (PR) } & rk1 & 4.833 & 1.670 & 0.924 & \multirow{2}{*}{0.842} & \multirow{2}{*}{0.941} & \multirow{2}{*}{0.906} \\
\hline & rk2 & 4.795 & 1.672 & 0.929 & & & \\
\hline
\end{tabular}




\begin{tabular}{|c|c|c|c|c|c|c|c|}
\hline Construct & Items & Mean & SD & $\begin{array}{l}\text { Factor } \\
\text { Loading }\end{array}$ & AVE & C.R. & $\begin{array}{c}\text { Cronbach' } \\
\text { s Alpha }\end{array}$ \\
\hline & rk3 & 4.571 & 1.708 & 0.898 & & & \\
\hline \multirow[t]{3}{*}{ Positive feedback (PF) } & pf1 & 4.352 & 1.774 & 0.957 & \multirow{3}{*}{0.877} & \multirow{3}{*}{0.955} & \multirow{3}{*}{0.930} \\
\hline & pf2 & 4.300 & 1.739 & 0.942 & & & \\
\hline & pf3 & 4.724 & 1.717 & 0.910 & & & \\
\hline \multirow{3}{*}{$\begin{array}{l}\text { Perceived promotion } \\
\text { innovativeness (PI) }\end{array}$} & pi1 & 4.719 & 1.519 & 0.935 & \multirow{3}{*}{0.886} & \multirow{3}{*}{0.959} & \multirow{3}{*}{0.936} \\
\hline & pi2 & 4.657 & 1.603 & 0.940 & & & \\
\hline & pi3 & 4.681 & 1.616 & 0.949 & & & \\
\hline \multirow{5}{*}{$\begin{array}{l}\text { Attitude toward Sharing } \\
\text { Location }\end{array}$} & at1 & 3.507 & 1.738 & 0.920 & \multirow{5}{*}{0.817} & \multirow{5}{*}{0.957} & \multirow{5}{*}{0.944} \\
\hline & at2 & 3.371 & 1.818 & 0.910 & & & \\
\hline & at3 & 3.638 & 1.844 & 0.927 & & & \\
\hline & at4 & 3.948 & 1.920 & 0.835 & & & \\
\hline & at5 & 3.610 & 1.874 & 0.924 & & & \\
\hline \multirow{3}{*}{$\begin{array}{l}\text { Continued sharing of location. } \\
\text { (CU) }\end{array}$} & Fre & 2.481 & 1.377 & 0.835 & \multirow{3}{*}{0.664} & \multirow{3}{*}{0.855} & \multirow{3}{*}{0.751} \\
\hline & ac1 & 2.910 & 1.965 & 0.881 & & & \\
\hline & ac $2 r$ & 5.229 & 1.797 & 0.721 & & & \\
\hline
\end{tabular}

Table 4. Correlations between research constructs

\begin{tabular}{lccccccccccc}
\hline & ATT & CU & IM & IC & PB & PI & RK & PF & PC & TM & TP \\
\hline ATT & 0.904 & & & & & & & & & & \\
CU & 0.714 & 0.815 & & & & & & & & & \\
IM & 0.737 & 0.560 & 0.923 & & & & & & & & \\
IC & 0.494 & 0.467 & 0.431 & 0.968 & & & & & & & \\
PB & 0.809 & 0.687 & 0.692 & 0.627 & 0.903 & & & & & & \\
PI & 0.523 & 0.419 & 0.390 & 0.303 & 0.540 & 0.941 & & & & & \\
RK & -0.212 & -0.124 & -0.048 & 0.142 & -0.053 & -0.105 & 0.917 & & & & \\
PF & 0.692 & 0.483 & 0.629 & 0.342 & 0.663 & 0.504 & -0.068 & 0.936 & & & \\
PC & -0.279 & -0.155 & -0.081 & 0.173 & -0.074 & -0.128 & 0.645 & -0.127 & 0.866 & & \\
TM & 0.268 & 0.209 & 0.058 & 0.134 & 0.233 & 0.238 & -0.234 & 0.136 & -0.173 & 0.848 & \\
TP & 0.519 & 0.369 & 0.342 & 0.335 & 0.469 & 0.286 & -0.100 & 0.375 & -0.142 & 0.497 & 0.873 \\
\hline
\end{tabular}

* Diagonal elements (in bold) are the square root of the average variance extracted

To assess the discriminant validity of measurements, we first used the FornellLarcker criterion. The results shown Table 4 indicate that the square root of the AVE 
of each construct was greater than other inter-construct correlations, which means discriminant validity was not an issue. We also use the Heterotrait-Monotrait ratio (HTMT) to assess the discriminant validity (Henseler, Ringle, \& Sarstedt, 2015). The result showed that all Heterotrait-Monotrait ratios of the correlations between the constructs were smaller than the threshold of 0.85 , which indicated that discriminant validity was not an issue for the constructs.

\section{Common Method Bias}

We used two tests to determine common method bias (CMB) to confirm the validity and quality of our data. First, we used Harman's one-factor test (Podsakoff, Mackenzie, Lee, \& Podsakoff, 2003), and the result of this test showed that the largest factor explained only $26 \%$ of the variance, which means CMB was not a serious issue. Second, we used a collinearity assessment approach (Kock, 2015) to indicate CMB. The result from the PLS showed that all VIF values generated for all constructs in a model were lower than the 3.3 threshold, which means the model was free from CMB (Kock, 2015).

\section{Hypothesis Testing Results}

Using SmartPLS 3.0 (Ringle et al., 2015), we estimated the path coefficient to test the hypotheses. To assess the significance of the path coefficients, we followed Hair et al.'s (2011) recommendation, with 5,000 bootstrap samples. The results of the PLS data analysis and hypotheses testing are shown in Table 5.

Table 5. Results of the PLS Data Analysis and Hypotheses

\begin{tabular}{clccc}
\hline $\begin{array}{c}\text { Hypo- } \\
\text { thesis }\end{array}$ & \multicolumn{1}{c}{ Relationship } & $\boldsymbol{\beta}$ & t & Results \\
\hline H1 & Privacy Concern $(+) \rightarrow$ Perceived Risk & $0.627^{* * *}$ & 12.233 & Supported \\
H2 & Trust in SNS provider $(-) \rightarrow$ Perceived Risk & 0.069 & 1.027 & Not supported \\
H3 & Trust in SNS members $(-) \rightarrow$ Perceived Risk & $-0.159^{*}$ & 2.441 & Supported \\
H4 & Impression mgm. $(+) \rightarrow$ Perceived Benefit & $0.518^{* * *}$ & 8.482 & Supported \\
H5 & Incentive $(+) \rightarrow$ Perceived Benefit & $0.403^{* * *}$ & 7.004 & Supported \\
H6 & Perceived Risk $(-) \rightarrow$ Attitude to LS & $-0.169 * * *$ & 3.723 & Supported \\
H7 & Perceived Benefit $(+) \rightarrow$ Attitude to LS & $0.800^{* * *}$ & 23.899 & Supported \\
H8 & Attitude toward LS $(+) \rightarrow$ Continued usage & $0.717^{* * *}$ & 16.237 & Supported \\
\hline Note: ${ }^{* * *} p<0.001, * * p<0.01,{ }^{*} p<0.05 ;$ using a significance level of 0.05, critical ratios (t-value) $>1.96$.
\end{tabular}


H1 was supported because privacy concern positively impacts perceived risk ( $\beta=0.627, p<0.001)$. Trust in the SNS provider and in SNS members was expected to have a negative impact on perceived risk. However, the results showed that only trust in SNS members had that impact $(\beta=-0.159, \mathrm{p}<0.05)$. Therefore, $\mathrm{H} 3$ was supported, and H2 was not supported $(\beta=0.069, \mathrm{p}>0.05)$. $\mathrm{H} 4$ and $\mathrm{H} 5$ were supported since both impression management and incentive positively influence perceived benefit $\left(\beta_{\mathrm{IM}}=0.518, \mathrm{p}_{\mathrm{IM}}<0.001\right.$ and $\beta_{\mathrm{IC}}=0.518$, $\left.\mathrm{pIC}_{\mathrm{IC}}<0.001\right)$. Perceived risk had a negative impact on attitude toward location sharing $(\beta=-0.169, \mathrm{p}<0.001)$, which means H6 was supported. $\mathrm{H} 7$ was supported since perceived risk had a strong impact on attitude toward location sharing $(\beta=0.800, \mathrm{p}<0.001)$. Finally, $\mathrm{H} 8$ was also supported since attitude toward location sharing highly influenced intention to engage in continued sharing of location ( $\beta=0.717, p<0.001$ ). Figure 2 also illustrates these hypotheses testing results in the conceptual model.

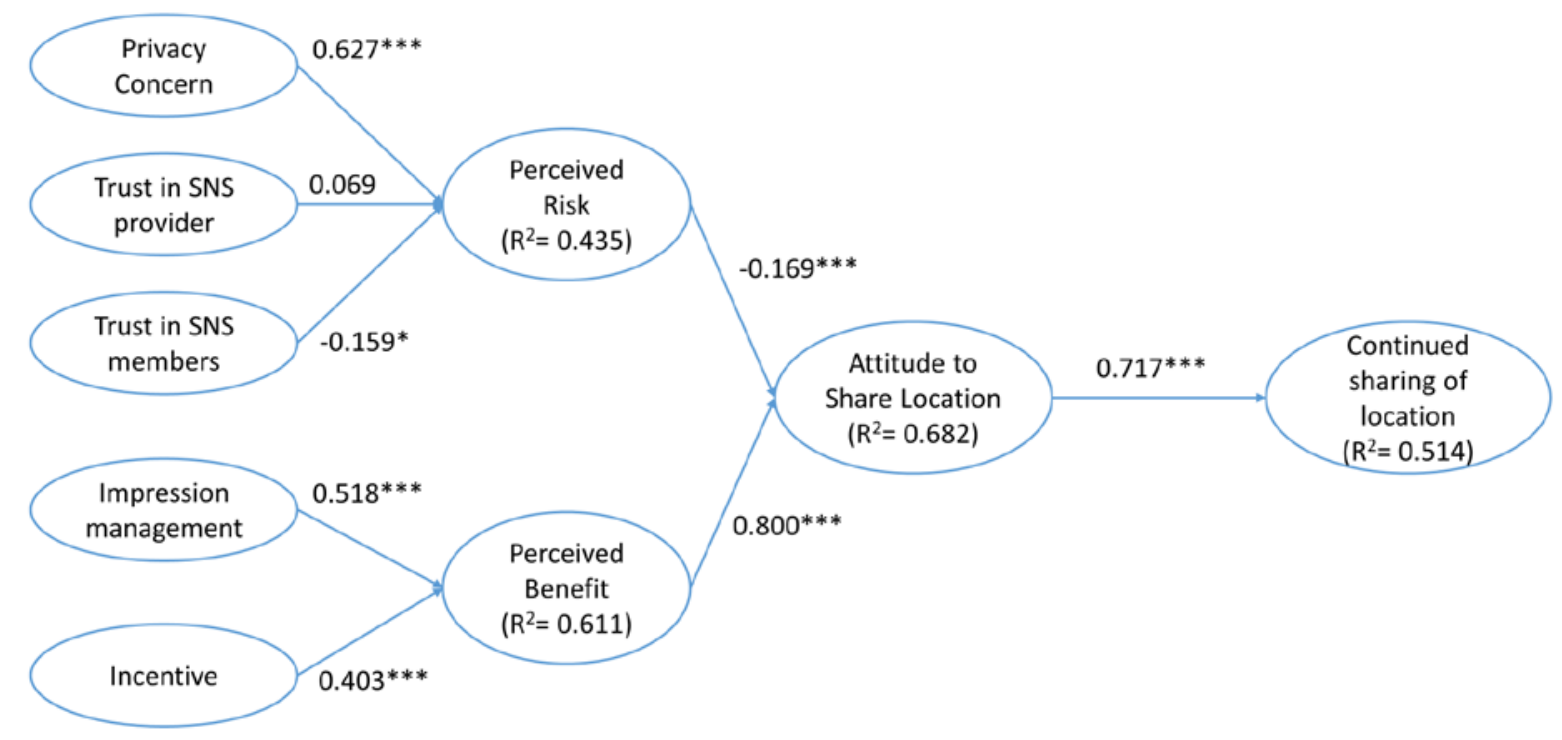

Figure 2. The results of PLS-SEM

\section{Moderating effects and Control Variables}

To test the moderating role of positive feedback and perceived promotion innovativeness on the relationship between attitude and continued sharing of location, as well as the role of the control variables on continued sharing of location, we used hierarchical regression analysis. The results in Table 6 show that positive feedback (PF) and perceived promotion innovativeness (PI) had a positive impact on the relationship between attitude toward location sharing and continued sharing of location ( $\beta$ PF x ATT 
$=0.215, \mathrm{p}$ PF $\times$ ATT $<0.001$ and $\beta$ PI $\times$ ATT $=0.195$, $\mathrm{P}$ PI x ATT $<0.001$ respectively). Therefore, H9 and H10 were supported. Concerning the impact of the control variables on continued sharing of location, we found that gender $(\beta=-0.114, p<0.05)$, education $(\beta=0.156, p<0.05)$ and average time spent using social network sites per day $(\beta=0.365$, $\mathrm{p}<0.001$ ) had significant impacts.

Table 6. Hierarchical regression results

\begin{tabular}{lccccc}
\hline \multirow{2}{*}{ Variables } & \multicolumn{5}{c}{ Dependent: Continuous to Share Location } \\
\cline { 2 - 6 } & Model 1 & Model 2 & Model 3 & Model 4 & Model 5 \\
\hline Gender & $-0.144^{*}$ & -0.082 & -0.090 & -0.086 & -0.086 \\
Age & 0.111 & 0.071 & 0.056 & 0.099 & 0.103 \\
Education & $0.156^{*}$ & $0.140^{*}$ & $0.144^{*}$ & $0.143^{*}$ & 0.158 \\
Income & -0.018 & -0.068 & -0.061 & -0.059 & -0.032 \\
Work Exp. & -0.161 & -0.063 & -0.049 & -0.070 & -0.070 \\
Time on SNSs & $0.365^{* * *}$ & $0.217^{* * *}$ & $0.222^{* * *}$ & $0.226^{* * *}$ & 0.215 \\
\hline ATT & & $0.394^{* * *}$ & $0.346^{* * *}$ & $0.487^{* * *}$ & $0.411^{* * *}$ \\
PI & & 0.105 & $0.178^{*}$ & & \\
PF & & & -0.059 & 0.053 \\
PI x ATT & & & & & \\
PF x ATT & & & & & $0.195^{* * *}$ \\
\hline R-squared & 0.212 & 0.385 & 0.419 & 0.379 & 0.416 \\
F values & 9.083 & 15.658 & 15.940 & 15.248 & 15.745 \\
(p value) & $(<0.001)$ & $(<0.001)$ & $(<0.001)$ & $(<0.001)$ & $(<0.001)$ \\
\hline
\end{tabular}

Note: ${ }^{* * *} p<0.001,{ }^{* *} p<0.01,{ }^{*} p<0.05$; ATT: Attitude toward Location sharing; PI Perceived promotion innovativeness; PF: Positive Feedback

\section{DISCUSSION AND IMPLICATIONS}

Location-based technologies and SNSs not only help users obtain local recommendations but also benefit businesses and help them promote their services effectively. Location sharing on SNSs provides businesses with many opportunities to foster eco-friendly business activities by increasing the efficiency of location promotion (Jang \& Lee, 2018). Therefore, it is crucial to research factors affecting SNS users' attitudes toward sharing their location as well as factors that help sustain that behavior. In line with the privacy calculus model, the risk-benefit assessment in this study indicated its significant impact on the attitude of SNS users when sharing their location. In detail, $\mathrm{H} 6$ and $\mathrm{H} 7$ show that perceived risk negatively affects attitude toward location sharing while perceived benefit positively affects that attitude. These findings are 
consistent with many previous studies that demonstrated that the impact of perceived benefit is stronger than that for privacy risk (Chen et al., 2017; Sun et al., 2015; Xu \& Gupta, 2009; Zhao et al., 2012). With H8 supported, this study has provided empirical evidence that a favorable attitude will strongly lead to continued sharing of location information on SNSs.

When it comes to factors affecting perceived risk, only privacy concern and trust in SNS members were found to play their important roles since $\mathrm{H} 1$ and $\mathrm{H} 3$ were supported. Surprisingly, H2 was not supported, which indicated that there is no significant relationship between trust in SNS providers and perceived risk, which is in contrast to the findings of Beldad and Citra Kusumadewi (2015). This may have been due to the fact that this technology is mature, and the number of unreliable service providers has decreased. Now, more providers in the market are reputable than was the case in the past. Therefore, users don't worry about privacy issues related to the provider although they still have other privacy concerns. H4 and H5 were supported, which demonstrated that impression management and incentive have a highly positive effect on perceived benefits. These findings are also consistent with previous research on impression management (Beldad \& Citra Kusumadewi, 2015) and incentive (Koohikamali et al., 2015; Xu et al., 2009; Zhao et al., 2012), which showed that impression management and incentive offer the greatest compensation for users' loss of privacy. The most interesting finding was that positive feedback has a positive impact on the relationship between attitude toward location sharing and intention to continue sharing of location (H9). This finding further supports the idea of Tsai et al. (2009), who suggested that receiving feedback is important to users' willingness to share their location. Also, different from impression management and incentive, positive feedback is mainly built from past experiences, which makes users feel they are being helpful to the online community and therefore tends to make them more proactive on SNSs. Finally, the current study found that perceived promotion innovativeness has a positive impact on the relationship between attitude toward location sharing and intention to continue sharing location (H10). These results also support the idea that perceived innovativeness has an impact on the behavioral outcomes of users (Chihui, 2009; Seliaman \& Al-Turki, 2012).

From a theoretical perspective, this study offered some important implications. First, this study contributes to the post-adoption literature when it investigates the relationship between attitude toward sharing location to intention to engage in continued location sharing behavior. When the location sharing technology was newly adopted, initial factors made location sharing inevitable. However, in today's fast- 
growing technology environment, the eventual success of a service provider lies in continuance usage (Bhattacherjee, 2001), and investigation of this phenomenon is crucial. Second, to the best of our knowledge, there have been only a few studies investigating the impact of positive feedback and perceived promotion innovativeness in the location sharing context. Previous research mostly studied benefit factors that resulted in location check-in but didn't pay attention to the factors that would sustain that behavior. Thus, the investigation of the moderating effects of positive feedback and perceived promotion innovativeness could also contribute to the post-adoption literature. Third, we also enrich the privacy calculus literature by providing evidence of costbenefit views of location sharing behavior under a single integrated model (Sun et al., 2015; Zhao et al., 2012).

From a managerial perspective, the findings reaffirmed that businesses should pay more attention to consumer perceptions of risk and benefit related to location sharing to promote their services more effectively on SNSs. Due to the fact that perceived benefit is much stronger than privacy risk, service providers should increase investments that provide more incentives that will entice customers. Specifically, this study also suggested that businesses can attract customers to come back and sustain their competitive advantage by increasing their perceived promotion innovativeness as well as giving customers more positive feedback related to their sharing their location. Companies should continuously change check-in promotion methods, thus diversifying the incentive for customers. In addition, companies could also rent third-party sources to give customers who shared their location positive feedback because they feel comfortable with being located not only by those on their social contact list but also by strangers (Tsai et al., 2009).

\section{REFERENCES}

Bagozzi, R. P. (2011). Measurement and meaning in information systems and organizational research: Methodological and philosophical foundations. MIS Quarterly, 261-292. https://doi.org/10.2307/23044044

Bansal, G., \& Gefen, D. (2010). The impact of personal dispositions on information sensitivity, privacy concern and trust in disclosing health information online. Decision Support Systems, 49(2), 138-150.

https://doi.org/10.1016/j.dss.2010.01.010

Barkhuus, L., \& Dey, A. (2003). Location-Based Services for Mobile Telephony: a study of user's privacy concerns. Paper presented at the 9th IFIP TC13 International Conference On Human-Computer Interaction, INTERACT 2003. 
Beldad, A., \& Citra Kusumadewi, M. (2015). Here’s my location, for your information: The impact of trust, benefits, and social influence on location sharing application use among Indonesian university students. Computers in Human Behavior, 49, 102-110. http://dx.doi.org/10.1016/j.chb.2015.02.047

Beldad, A., de Jong, M., \& Steehouder, M. (2011). I trust not therefore it must be risky: Determinants of the perceived risks of disclosing personal data for e-government transactions. Computers in Human Behavior, 27(6), 2233-2242. http://dx.doi.org/10.1016/j.chb.2011.07.002

Bhattacherjee, A. (2001). Understanding information systems continuance: An expectation-confirmation model. MIS Quarterly, 25(3), 351-370.

Bilogrevic, I., Huguenin, K., Mihaila, S., Shokri, R., \& Hubaux, J.-P. (2015). Predicting users' Motivations behind Location check-ins and utility implications of privacy protection mechanisms. Paper presented at the 22nd Network and Distributed System Security Symposium (NDSS" 15). https://doi.org/10.14722/ndss.2015.23032

Boyd, D. M., \& Ellison, N. B. (2007). Social network sites: Definition, history, and scholarship. Journal of Computer-Mediated Communication, 13(1), 210-230. https://doi.org/10.1109/emr.2010.5559139

Buchanan, T., Paine, C., Joinson, A. N., \& Reips, U.-D. (2007). Development of measures of online privacy concern and protection for use on the Internet. Journal of the American Society for Information Science and Technology, 58(2), 157-165. https://doi.org/10.1002/asi.20459

Chang, C.-W., \& Chen, G. M. (2014). College students' disclosure of location-related information on Facebook. Computers in Human Behavior, 35, 33-38. https://doi.org/10.1016/j.chb.2014.02.028

Chen, J. V., Elakhdary, M. A., \& Ha, Q.-A. (2019). The continuance use of social network sites for political participation: Evidences from Arab countries. Journal of Global Information Technology Management, 22(3), 156-178. https://doi.org//10.1080/1097198X.2019.1642021

Chen, J. V., Su, B.-c., \& Quyet, H. M. (2017). Users' intention to disclose location on location-based social network sites (LBSNS) in mobile environment: Privacy calculus and Big Five. International Journal of Mobile Communications, 15(3), 329-353. https://doi.org/10.1504/IJMC.2017.083465

Chen, S.-C., \& Li, S.-H. (2010). Consumer adoption of e-Service: Integrating technology readiness with the theory of planned behavior. African Journal of Business Management, 4(16), 3556-3563. 
Chihui, C. (2009). Perceived innovativeness, perceived convenience and TAM: Effects on mobile knowledge management. Paper presented at the Third International Conference on Multimedia and Ubiquitous Engineering, 2009. MUE'09.

Chin, W. W. (1998). Issues and opinions on structural equation modeling. MIS Quarterly, 22(1), 7-10.

Chorley, M. J., Whitaker, R. M., \& Allen, S. M. (2015). Personality and location-based social networks. Computers in Human Behavior, 46(0), 45-56.

http://dx.doi.org/10.1016/j.chb.2014.12.038

Christofides, E., Muise, A., \& Desmarais, S. (2009). Information disclosure and control on Facebook: Are they two sides of the same coin or two different processes? CyberPsychology \& Behavior, 12(3), 341-345.

https://doi.org/10.1089/cpb.2008.0226

Dienlin, T., \& Metzger, M. J. (2016). An extended privacy calculus model for SNSs: Analyzing self-disclosure and self-withdrawal in a representative US sample. Journal of Computer-Mediated Communication, 21(5), 368-383. https://doi.org/10.1111/jcc4.12163

Dinev, T., \& Hart, P. (2006). An extended privacy calculus model for e-commerce transactions. Information Systems Research, 17(1), 61-80-80. https://doi.org/10.1287/isre.1060.0080

Erickson, T., \& Kellogg, W. A. (2000). Social translucence: An approach to designing systems that support social processes. ACM transactions on computer-human interaction (TOCHI), 7(1), 59-83. https://doi.org/10.1145/344949.345004

Falkenreck, C., \& Wagner, R. (2011). The impact of perceived innovativeness on maintaining a buyer-seller relationship in health care markets: A cross-cultural study. Journal of Marketing Management, 27(3-4), 225-242. https://doi.org/10.1080/0267257x.2011.545672

Fang, J., Shao, P., \& Lan, G. (2009). Effects of innovativeness and trust on web survey participation. Computers in Human Behavior, 25(1), 144-152. https://doi.org/10.1016/j.chb.2008.08.002

Fornell, C., \& Larcker, D. (1981). Evaluating structural equation models with unobservable variables and measurement error. Journal of Marketing Research, 18(3), 39-50. https://doi.org/10.2307/3150979

Fortes, N., \& Rita, P. (2016). Privacy concerns and online purchasing behaviour: Towards an integrated model. European Research on Management and Business Economics, 22(3), 167-176. https://doi.org/10.1016/j.iedeen.2016.04.002

Fu, F. Q., \& Elliott, M. T. (2013). The moderating effect of perceived product innovativeness and product knowledge on new product adoption: An integrated 
model. Journal of Marketing Theory and Practice, 21(3), 257-272.

https://doi.org/10.2753/mtp1069-6679210302

Fusco, S. J., Michael, K., \& Michael, M. (2010). Using a social informatics framework to study the effects of location-based social networking on relationships between people: A review of literature. Paper presented at the 2010 IEEE International Symposium on Technology and Society, Wollongong, NSW, Australia.

Giovanis, A. N., Binioris, S., \& Polychronopoulos, G. (2012). An extension of TAM model with IDT and security/privacy risk in the adoption of internet banking services in Greece. EuroMed Journal of Business, 7(1), 24-53. https://doi.org/10.1108/14502191211225365

Ha, Q.-A., \& Chen, J.-C. V. (2016). Strategy to promote location sharing on social network under perspectives of culture. Paper presented at the Pacific Asia Conference on Information Systems, PACIS 2016, Chiayi. https://aisel.aisnet.org/pacis2016/91

Hair, J. F., Ringle, C. M., \& Marko, S. (2011). PLS-SEM: Indeed a silver bullet. Journal of Marketing Theory and Practice, 19(2), 139-151. https://doi.org/10.2753/mtp1069-6679190202

Henseler, J., Ringle, C. M., \& Sarstedt, M. (2015). A new criterion for assessing discriminant validity in variance-based structural equation modeling. Journal of the Academy of Marketing Science, 43(1), 115-135. https://doi.org/10.1007/s11747-014-0403-8

Hsu, M.-H., Chang, C.-M., Chu, K.-K., \& Lee, Y.-J. (2014). Determinants of repurchase intention in online group-buying: The perspectives of DeLone \& McLean IS success model and trust. Computers in Human Behavior, 36, 234-245. https://doi.org/10.1016/j.chb.2014.03.065

Hsu, M.-H., Yen, C.-H., Chiu, C.-M., \& Chang, C.-M. (2006). A longitudinal investigation of continued online shopping behavior: An extension of the theory of planned behavior. International Journal of Human-Computer Studies, 64(9), 889-904. https://doi.org/10.1016/j.ijhcs.2006.04.004

Jang, S. H., \& Lee, C. W. (2018). The impact of location-based service factors on usage intentions for technology acceptance: The moderating effect of innovativeness. Sustainability, 10(6), 1-18. https://doi.org/10.3390/su10061876

Johnson, B. K., \& Van Der Heide, B. (2015). Can sharing affect liking? Online taste performances, feedback, and subsequent media preferences. Computers in Human Behavior, 46(0), 181-190. http://dx.doi.org/10.1016/j.chb.2015.01.018 
Jung, Y., \& Park, J. (2018). An investigation of relationships among privacy concerns, affective responses, and coping behaviors in location-based services. International Journal of Information Management, 43, 15-24. https://doi.org/10.1016/j.ijinfomgt.2018.05.007

Keith, M. J., Babb Jr, J. S., Furner, C. P., \& Abdullat, A. (2010). Privacy assurance and network effects in the adoption of location-based services: An iPhone experiment. Paper presented at the ICIS 2010.

Keith, M. J., Thompson, S. C., Hale, J., Lowry, P. B., \& Greer, C. (2013). Information disclosure on mobile devices: Re-examining privacy calculus with actual user behavior. International Journal of Human-Computer Studies, 71(12), 1163-1173. https://doi.org/10.1016/j.ijhcs.2013.08.016

Kim, E., Tang, L., \& Bosselman, R. (2018). Measuring customer perceptions of restaurant innovativeness: Developing and validating a scale. International Journal of Hospitality Management, 74, 85-98.

https://doi.org/10.1016/j.ijhm.2018.02.018

Kock, N. (2015). Common method bias in PLS-SEM. International Journal of eCollaboration, 11(4), 1-10. https://doi.org/10.4018/ijec.2015100101

Koohikamali, M., Gerhart, N., \& Mousavizadeh, M. (2015). Location disclosure on LBSNAs: The role of incentives on sharing behavior. Decision Support Systems, 71(0), 78-87. http://dx.doi.org/10.1016/j.dss.2015.01.008

Krasnova, H., Veltri, N. F., \& Günther, O. (2012). Self-disclosure and privacy calculus on social networking sites: The role of culture. Business \& Information Systems Engineering, 4(3), 127-135. https://doi.org/10.1007/s12599-012-0216-6

Lafferty, B. A., \& Goldsmith, R. E. (2004). How influential are corporate credibility and endorser attractiveness when innovators react to advertisements for a new high-technology product? Corporate Reputation Review, 7(1), 24-36. https://doi.org/10.1057/palgrave.crr.1540209

Laufer, R. S., \& Wolfe, M. (1977). Privacy as a concept and a social issue: A multidimensional developmental theory. Journal of Social Issues, 33(3), 22-42. 10.1111/j.1540-4560.1977.tb01880.x

Leary, M. R., \& Kowalski, R. M. (1990). Impression management: A literature review and two-component model. Psychological Bulletin, 107(1), 34.

https://doi.org/10.1037//0033-2909.107.1.34

Lee, M.-C., \& Tsai, T.-R. (2010). What drives people to continue to play online games? An extension of technology model and theory of planned behavior. International Journal of Human-Computer Interaction, 26(6), 601-620.

https://doi.org/10.1080/10447311003781318 
Li, Y. (2012). Theories in online information privacy research: A critical review and an integrated framework. Decision Support Systems, 54(1), 471-481. https://doi.org/10.1016/j.dss.2012.06.010

Limayem, M., \& Cheung, C. M. K. (2008). Understanding information systems continuance: The case of Internet-based learning technologies. Information \& Management, 45(4), 227-232. https://doi.org/10.1016/j.im.2008.02.005

Lin, T.-H., Lu, H.-P., Hsiao, K.-L., \& Hsu, H.-H. (2014). Continuance intention of Facebook check-in service users: An integrated model. Social Behavior and Personality: An International Journal, 42(10), 1745-1760. https://doi.org/10.2224/sbp.2014.42.10.1745

Lindqvist, J., Cranshaw, J., Wiese, J., Hong, J., \& Zimmerman, J. (2011). I'm the mayor of my house: examining why people use foursquare-a social-driven location sharing application. Paper presented at the Proceedings of the SIGCHI conference on human factors in computing systems.

Liu, D., \& Brown, B. B. (2014). Self-disclosure on social networking sites, positive feedback, and social capital among Chinese college students. Computers in Human Behavior, 38, 213-219. https://doi.org/10.1016/j.chb.2014.06.003

Mahmod, J. A., Ibrahim, A., \& Yousif, R. A. (2010). The Impact of marketing innovation on creating a sustainable competitive advantage: The case of private commercial banks in Jordan. Asian Journal of Marketing, 4, 113-130. https://doi.org/10.3923/ajm.2010.113.130

Malhotra, N. K., Kim, S. S., \& Agarwal, J. (2004). Internet users' information privacy concerns (IUIPC): The construct, the scale, and a causal model. Information Systems Research, 15(4), 336-355. https://doi.org/10.1287/isre.1040.0032

McLain, D. L., \& Hackman, K. (1999). Trust, risk, and decision-making in organizational change. Public Administration Quarterly, 152-176.

Min, J., \& Kim, B. (2015). How are people enticed to disclose personal information despite privacy concerns in social network sites? The calculus between benefit and cost. Journal of the Association for Information Science and Technology, 66(4), 839-857. https://doi.org/10.1002/asi.23206

Mouakket, S. (2015). Factors influencing continuance intention to use social network sites: The Facebook case. Computers in Human Behavior, 53, 102-110. https://doi.org/10.1016/j.chb.2015.06.045

O’Cass, A., \& Carlson, J. (2012). An e-retailing assessment of perceived websiteservice innovativeness: Implications for website quality evaluations, trust, 
loyalty and word of mouth. Australasian Marketing Journal, 20(1), 28-36. https://doi.org/10.1016/j.ausmj.2011.10.012

Patil, S., Norcie, G., Kapadia, A., \& Lee, A. (2012). "Check out where I am!": locationsharing motivations, preferences, and practices. Paper presented at the CHI '12 Extended Abstracts on Human Factors in Computing Systems, Austin, Texas, USA.

Pengnate, S. F., \& Sarathy, R. (2017). An experimental investigation of the influence of website emotional design features on trust in unfamiliar online vendors. Computers in Human Behavior, 67, 49-60.

https://doi.org/10.1016/j.chb.2016.10.018

Podsakoff, P. M., Mackenzie, S. B., Lee, J. Y., \& Podsakoff, N. P. (2003). Common method biases in behavioral research: A critical review of the literature and recommended remedies. Journal of Applied Psychology, 88(5), 839-903.

Puttaswamy, K. P., \& Zhao, B. Y. (2010). Preserving privacy in location-based mobile social applications. Paper presented at the Proceedings of the Eleventh Workshop on Mobile Computing Systems \& Applications.

Raschke, R. L., Krishen, A. S., \& Kachroo, P. (2014). Understanding the components of information privacy threats for location-based services. Journal of Information Systems, 28(1), 227-242. https://doi.org/10.2308/isys-50696

Ringle, C. M., Sven, W., \& Jan-Michael, B. (2015). SmartPLS. Bönningstedt: SmartPLS GmbH.

Seliaman, M. E., \& Al-Turki, M. (2012). Mobile learning adoption in Saudi Arabia. World Academy of Science, Engineering and Technology, 69(9), 391-293.

Sheehan, K. B., \& Hoy, M. G. (2000). Dimensions of privacy concern among online consumers. Journal of Public Policy \& Marketing, 19(1), 62-73. ttps://doi.org/10.1509/jppm.19.1.62.16949

Smith, H. J., Milberg, S. J., \& Burke, S. J. (1996). Information privacy: Measuring individuals' concerns about organizational practices. MIS quarterly, 167-196.

Stone, E. F., Gueutal, H. G., Gardner, D. G., \& McClure, S. (1983). A field experiment comparing information-privacy values, beliefs, and attitudes across several types of organizations. Journal of Applied Psychology, 68(3), 459. https://doi.org/10.1037/0021-9010.68.3.459

Sun, Y., Wang, N., Shen, X.-L., \& Zhang, J. X. (2015). Location information disclosure in location-based social network services: Privacy calculus, benefit structure, and gender differences. Computers in Human Behavior, 52, 278-292. https://doi.org/10.1016/j.chb.2015.06.006 
Tsai, J. Y., Kelley, P., Drielsma, P., Cranor, L. F., Hong, J., \& Sadeh, N. (2009). Who's viewed you?: The impact of feedback in a mobile location-sharing application. Paper presented at the Proceedings of the SIGCHI Conference on Human Factors in Computing Systems.

Tsai, J. Y., Kelley, P. G., Cranor, L. F., \& Sadeh, N. (2010). Location-sharing technologies: Privacy risks and controls. TPRC 2019, 6, 119.

Van Slyke, C., Shim, J., Johnson, R., \& Jiang, J. J. (2006). Concern for information privacy and online consumer purchasing. Journal of the Association for Information Systems, 7(6), 16. https://doi.org/10.17705/1jais.00092

Venkatesh, V., Morris, M. G., Gordon, B. D., \& Davis, F. D. (2003). User Acceptance of Information Technology: Toward a Unified View. MIS Quarterly, 27(3), 425478. https://doi.org/10.2307/30036540

Wagner, D., Lopez, M., Doria, A., Pavlyshak, I., Kostakos, V., Oakley, I., \& Spiliotopoulos, T. (2010). Hide and seek: location sharing practices with social media. Paper presented at the Proceedings of the 12th international conference on Human computer interaction with mobile devices and services.

Wang, E. S.-T., \& Lin, R.-L. (2017). Perceived quality factors of location-based apps on trust, perceived privacy risk, and continuous usage intention. Behaviour \& Information Technology, 36(1), 2-10. https://doi.org/10.1080/0144929x.2016.1143033

Wang, S. S., \& Stefanone, M. A. (2013). Showing off? Human mobility and the interplay of traits, self-disclosure, and Facebook check-ins. Social Science Computer Review, 0894439313481424.

https://doi.org/10.1177/0894439313481424

Wang, T., Duong, T. D., \& Chen, C. C. (2016). Intention to disclose personal information via mobile applications: A privacy calculus perspective. International Journal of Information Management, 36(4), 531-542.

https://doi.org/10.1016/j.ijinfomgt.2016.03.003

Wang, Y., Wang, X., Liu, H., Xie, X., Wang, P., \& Lei, L. (2018). Selfie posting and self-esteem among young adult women: A mediation model of positive feedback and body satisfaction. Journal of Health Psychology, 1359105318787624. (in press) https://doi.org/10.1177/1359105318787624

Waters, S., \& Ackerman, J. (2011). Exploring privacy management on Facebook: Motivations and Perceived consequences of voluntary disclosure. Journal of Computer-Mediated Communication, 17(1), 101-115.

http://doi.org/10.1111/j.1083-6101.2011.01559.x 
Wu, Y., Balasubramanian, S., \& Mahajan, V. (2004). When is a preannounced new product likely to be delayed? Journal of Marketing, 68(2), 101-113. https://doi.org/10.1509/jmkg.68.2.101.27792

Xu, F., Michael, K., \& Chen, X. (2013). Factors affecting privacy disclosure on social network sites: an integrated model. Electronic Commerce Research, 13(2), 151168. https://doi.org/10.1007/s10660-013-9111-6

$\mathrm{Xu}, \mathrm{H}$. (2010). Locus of control and location privacy: An empirical study in Singapore. Journal of Global Information Technology Management, 13(3), 63-87. https://doi.org/10.1080/1097198X.2010.10856520

Xu, H., \& Gupta, S. (2009). The effects of privacy concerns and personal innovativeness on potential and experienced customers' adoption of location-based services. Electronic Markets, 19(2-3), 137-149. https://doi.org/10.1007/s12525-009-0012-4

Xu, H., Teo, H.-H., \& Tan, B. (2005). Predicting the adoption of location-based services: The role of trust and perceived privacy risk. ICIS 2005 proceedings, 71.

Xu, H., Teo, H.-H., Tan, B. C., \& Agarwal, R. (2009). The role of push-pull technology in privacy calculus: The case of location-based services. Journal of Management Information Systems, 26(3), 135-174. https://doi.org/10.2753/MIS0742-1222260305

Yavuz, R., \& Toker, A. (2014). Location sharing on social networks: Implications for marketing. Marketing Intelligence \& Planning, 32(5), 567-585. https://doi.org/10.1108/MIP-05-2013-0084

Yun, H., Han, D., \& Lee, C. C. (2013). Understanding the use of location-based service applications: Do privacy concerns matter? Journal of Electronic Commerce Research, 14(3), 215-230.

Zhao, L., Lu, Y., \& Gupta, S. (2012). Disclosure intention of location-related information in location-based social network services. International Journal of Electronic Commerce, 16(4), 53-90. https://doi.org/10.2753/jec1086-4415160403

Zhou, T. (2011). The impact of privacy concern on user adoption of location-based services. Industrial Management \& Data Systems, 111(2), 212-226. https://doi.org/10.1108/02635571111115146

Zhou, T. (2012). Examining location-based services usage from the perspectives of unified theory of acceptance and use of technology and privacy risk. Journal of Electronic Commerce Research, 13(2), 135-144. 
Zhou, T. (2013). Examining continuous usage of location-based services from the perspective of perceived justice. Information Systems Frontiers, 15(1), 141-150. https://doi.org/10.1007/s10796-011-9311-3

Zhou, T. (2017). Understanding location-based services users' privacy concern: An elaboration likelihood model perspective. Internet Research, 27(3), 506-519. https://doi.org/10.1108/IntR-04-2016-0088

Zhou, T., \& Li, H. (2014). Understanding mobile SNS continuance usage in China from the perspectives of social influence and privacy concern. Computers in Human Behavior, 37, 283-289. https://doi.org/10.1016/j.chb.2014.05.008

Jeng-Chung Victor Chen is a distinguished professor of the Institute of International Management, College of Management, National Cheng Kung University, Taiwan. He received a PhD in CIS from the University of Hawaii, USA. He has published over 70 papers in refereed journals, including Information \& Management, Decision Support Systems, European Journal of Information Systems, Computers in Human Behavior, Journal of Computer Information Systems, International Journal of Mobile Communications, Journal of Systems and Software, Industrial Management and Data Systems, International Journal of Energy Research, Computer Standards \& Interfaces, and many others.

Quang-An Ha (Corresponding author) is currently a $\mathrm{PhD}$ candidate of the Institute of International Management, College of Management, National Cheng Kung University, Taiwan. His researches have appeared in Computers in Human Behavior, International Journal of Mobile Communications, International Journal of Energy Economics and several international conference proceedings. His research interests include social commerce, cyber psychology, human-computer interaction. 